\title{
Type of sexual intercourse experience and suicidal ideation, plans, and attempts among youths: a cross-sectional study in South Korea
}

Geum Hee Kim ${ }^{1,2}$, Hyeong Sik Ahn²* and Hyun Jung Kim²

\begin{abstract}
Background: Despite abundant theoretical evidence of higher rates of suicide among lesbian, gay, and bisexual (LGB) youths, little is known about the relationship between suicide and types of sexual intercourse experience in youths. This study examines the association between the type of intercourse experience and suicide risk outcomes (SROs: suicidal ideation, plans for suicide, suicidal attempts) from the Korea Youth Risk Behavior Web-based Survey.

Methods: We analyzed cross-sectional data from 146,621 students aged 12-17 years for the years 2012 and 2013. We defined lesbian, gay, or bisexual youth as youths who engaged in a type of sexual intercourse (same-sex or both-sex intercourse). A chi-square test and logistic regression analysis were used to evaluate the association between intercourse experience and SROs.

Results: The results showed that the prevalence of suicidal ideation was higher among youths with same-sex intercourse experience (45.9\% for females, 33.7\% for males) than among youths with opposite-sex intercourse experience (42.2\% for females, $23.8 \%$ for males) and those with no experience in intercourse (21.0\% for females, 12. $7 \%$ for males). After adjusting for revealed risk factors that were associated with suicide risks, among males, suicide risks based on intercourse experience seemed to increase in the following order: no experience in sexual intercourse, opposite-sex, same-sex, and then both-sexes sexual intercourse experience. Same- and both-sexes intercourse related SROs are strongly linked to violence (being physically assaulted, threatened, or bullied) and sexually transmitted diseases (STDs), including HIV infection. Those having no sexual intercourse experience showed the least probability of suicide risks among youths.

Conclusion: The SROs of youths with same-sex or both-sex intercourse experience had strong associations with gender (males), violence, and STDs. Therefore, school educators must continue to advocate for and to implement LGB inclusive policies and programs in order to promote safe and supportive learning environments where all students are protected from health risk behaviors.
\end{abstract}

Keywords: Lesbian, Gay, Bisexual, Youths, Sexual intercourse, Suicide, Violence, Sexually transmitted diseases

\footnotetext{
* Correspondence: ahnhann@gmail.com

${ }^{2}$ Department of Preventive Medicine, College of Medicine, Korea University,

73, Inchon-ro, Seongbuk-gu, Seoul 02841, Korea

Full list of author information is available at the end of the article
} 


\section{Background}

Suicide is the leading cause of mortality among Korean youths aged 10-19 years, which demonstrates that suicide among youths is a significant issue [1]. Suicidal behavior includes suicidal ideation, plans, attempts, and death through a medically serious action [2]. Variables that influence the suicidal behavior were depression and ever having had sexual intercourse as youths [2]. Media reports convey the message that lesbian, gay, or bisexual (LGB) youths have much greater rates of suicide than non-LGB youths [3]. LGB youths experience stress and depression during the formation of their sexual identity. They have been reported to demonstrate suicidal attempts 2-3 times more often than heterosexual youths $[4,5]$. The prevalence of suicide in youths who engaged in a type of sexual intercourse (having had intercourse with the opposite-sex, same-sex, or both-sex intercourse) has been known to differ among races and countries [3]. To date, most studies on the outcomes for the risk of suicide as a result of sexual intercourse experience have been reported in western countries; very few studies have been done in Asian countries [6-8]. Although there have been several small studies elucidating the association between homosexuality and suicide, there have been no studies on the prevalence of the type of sexual intercourse or suicidal behavior by sexual intercourse experience in South Korean youths [8]. Therefore, we investigated the status of youths by type of sexual intercourse among all middle and high school students in South Korea. We assessed the direct effects of suicide risk outcomes (SROs: suicidal ideation, plans for suicide, suicidal attempts) due to type of sexual intercourse experience while controlling for other confounders known to affect SROs among youths. The objective of this study was to analyze and interpret the association between the prevalence of youths with sexual intercourse experience and SROs, by using the Korea Youth Risk Behavior Web-based Survey (KYRBS) database from the years 2012 and 2013.

\section{Methods}

\section{Study design and population}

This was a cross-sectional study using Korea's representative Youth Risk Behavior Web-based Survey (KYRBS) database from 2012 and 2013. The study consisted of 146,621 students (from grades 7 to 12 , aged 12 to 17 years) who were sampled randomly. Sampling for the KYRBS consisted of stratified randomization. The population consisted of stratified parameters, such as region and grade level. As for strata of variables, the number of sampled schools was distributed based on city, county, size of the city, and school type using a proportional allocation method to match population and sample compositions. At the stage of sample extraction, we used a stratified 2-stage cluster sample design, with the unit for primary extraction being the school and the unit for secondary extraction being the intact classes [9].

\section{Measures}

KYRBS is a school-based, self-report from the Ministry of Education, Ministry of Health and Welfare, and the Korea Centers for Disease Control and Prevention (KCDC) to understand health behaviors among youths. The KYRBS has 126 questions that assess 15 domains of health risk behavior, such as smoking, drinking, obesity, sexual intercourse, suicidal behavior, and violence.

\section{Type of sexual intercourse}

This was measured by the question: "During your life, with whom have you had sexual intercourse experience?" Response options included I have never had sexual intercourse, opposite-sex, and same-sex intercourse experience. We classified students as having had intercourse with the opposite-sex, intercourse with the same-sex, intercourse with the both-sex, no experience in intercourse (no contact).

\section{Suicide risk outcomes (SROs)}

We measured three dichotomous questions: seriously considered suicide ideation, made a plan for suicide plans, and attempted suicide at least once during the past 12 months prior to the survey.

\section{Control variables}

We selected risk factors associated with type of sexual intercourse or SROs based on current literature $[2,5,10-15]$. We included the following risk factors occurring during the past 12 months prior to the survey. To measure violence, we used the question: "Have you had any experience of receiving treatment at a hospital for violence (being physically assaulted, threatened, or bullied) from friends, superiors, or adults?" We measured six socioeconomic-related factors; gender, grade, type of school, region, self-reported academic achievement, and perceived household economic status. We measured family structure by asking one question; living with both parents (both parents), living with mother (mother only), living with father (father only), or not living with parents (neither parent). We included questions about two different health risk behaviors. To calculate smoking habits, the question: "During the past 30 days prior to the survey, have you smoked at least one cigarette?" was used. To determine the effect of drinking, we included the following question: "During the past 12 months prior to the survey, have you had at least one alcoholic drink alone?" We also included a variable to assess the evidence of an association with suicidal behavior: subjective perception of body habits, which is perceiving oneself as being very obese as 
opposed to being overweight, underweight, or normal (perceived obesity). Responses for subjective perception of health status were quite poor or poor as opposed to excellent, very good, or good (perceived health status). Finally, sexual health risk behavior was assessed with a single measure ("Have you ever been diagnosed with sexually transmitted diseases (STDs) including HIV infection from sexual intercourse?").

\section{Statistical analysis}

Using IBM SPSS Statistics Version 20, we conducted statistical analysis on weighted data in order to interpret the data in a way that represented all students in grades 7-12 who were attending public schools in South Korea in 2012 and 2013. We merged the years of available data from 2012 and 2013 from the KYRBS.

We performed all statistical analyses on weighted data to adjust for subjects' nonresponses and to account for the complex sampling design of the KYRBS. We compared the distribution of demographic characteristics (Table 1) and SROs (Table 2) by sexual intercourse experience using a chi-square test. The demographics of the subjects were shown as an unweighted sample size and a weighted percentage using composite sample descriptive statistics.

We used simple logistic regression analysis to examine the associations between SROs and type of sexual intercourse experience, along with all control variables. After which, we performed a multiple logistic regression analyses in order to predict SROs after controlling for family structure, health risk behaviors (smoking, drinking, perceived obesity, and perceived health status), STDs, and experiences of violence [15]. We were presented unadjusted and adjusted odds ratios (ORs) and 95\% confidence intervals (CIs) by gender (Table 3 ).

\section{Results}

The prevalence of type of sexual intercourse in youths

Table 1 demonstrates the prevalence of sexual intercourse in youths based on demographics. Among the 146,621 students (from grades 7 to 12 ), $3.9 \%$ had opposite-sex intercourse (2.2\% for females, $5.5 \%$ for males), $0.5 \%$ had same-sex intercourse ( $0.3 \%$ for females, $0.6 \%$ males), and $0.5 \%$ had intercourse with both sexes $(0.3 \%$ for females, $0.6 \%$ for males).

\section{The prevalence of SROs in youths}

Table 2 presents the prevalence of SROs. The prevalence was higher among youths with same-sex intercourse experience for suicidal ideation (45.9\% for females, $33.7 \%$ for males), plans for suicide (34.3\% for females, $22.0 \%$ for males), and suicidal attempts (28.4\% for females, $17.0 \%$ for males) than among youths with opposite-sex intercourse experience $(p<0.001)$. The prevalence was higher among youths who had STDs for suicidal ideation (61.2\% for females, $44.6 \%$ for males), plans for suicide (44.4\% for females, $34.5 \%$ for males), and suicidal attempts $(42.8 \%$ for females, $24.7 \%$ for males) than for youths who did not have STDs. Additionally, the prevalence for suicidal ideation was higher among youths who were victims of violence $(55.3 \%$ for females, $35.1 \%$ for males) than for youths who had not been victims of violence ( $\mathrm{p}<0.001)$. In our study, SROs based on sexual intercourse experience seemed to increase in the following order: no experience in intercourse, opposite-sex intercourse, same-sex intercourse, and then both-sexes intercourse experience (Table 2).

\section{The associations between type of sexual intercourse and SROs}

In unadjusted analyses examining lesbian, gay, or bisexual youth defined by type of sexual intercourse, except for suicide ideation among females, we found that most youths with same-sex intercourse and both-sex intercourse compared with opposite-sex intercourse had increased odds of all SROs, with the odds ratios (ORs) ranging from 2.27 (95\% confidence interval $[\mathrm{CI}]=1.66-$ 3.09) for plans of suicide among females with same-sex intercourse to 2.58 (95\% CI $=1.95-3.40)$ for suicidal attempts among males with same-sex intercourse (all $p<0.001$ ). All youths who had STDs increased the odds of all SROs compared to youths who had not been diagnosed with STDs (Table 2).

In the adjusted analyses, we added all the control variables (family structure, health risk behaviors, STDs including HIV infection, and experiences of violence) simultaneously. Compared to males with opposite-sex intercourse experience only, males who had experienced same-sex or both-sex intercourse differed significantly in their odds of SROs. On the other hand, among females, we found that females with same-sex and both-sex intercourse experience, compared to those with opposite-sex intercourse, had reduced odds of suicide ideation. In addition, females with same-sex and both-sex intercourse experience did not differ in suicide planning and attempts when compared to females with opposite-sex intercourse only. Males with same-sex intercourse experience were higher in suicidal ideation (adjusted odds ratio $[\mathrm{AOR}]=1.29 ; 95 \% \mathrm{CI}=1.01-1.64)$, plans for suicide $(\mathrm{AOR}=1.45 ; 95 \% \mathrm{CI}=1.10-1.92)$, and suicidal attempts $(\mathrm{AOR}=1.69 ; 95 \% \mathrm{CI}=1.22-2.35)$ compared with males who had only experienced opposite-sex intercourse. Males suffering from STDs, including HIV infection, were higher in suicidal ideation (AOR $=1.35 ; 95 \% \mathrm{CI}=1.10-1.66)$, plans for suicide (AOR $=1.80 ; 95 \% \mathrm{CI}=1.40-2.32)$, and suicidal attempts $(\mathrm{AOR}=1.34 ; 95 \% \mathrm{CI}=1.02-1.76)$ compared to males who did not have an STD. SROs were higher 
Table 1 Demographic characteristics by gender and the type of sexual intercourse experience: KYRBS

\begin{tabular}{|c|c|c|c|c|c|c|c|c|}
\hline \multirow{3}{*}{$\begin{array}{l}\text { Merged } 2012 \sim 2013 \\
n=146,621 \\
\text { Characteristics }\end{array}$} & \multicolumn{8}{|c|}{ Type of sexual intercourse, no. $(\%)^{\ddagger}$} \\
\hline & \multicolumn{4}{|c|}{ Females, $n=71,745$} & \multicolumn{4}{|c|}{ Males, $n=74,876$} \\
\hline & No Contact & Opposite & Same & Both & No Contact & Opposite & Same & Both \\
\hline \multicolumn{9}{|l|}{ Socioeconomic factors } \\
\hline \multicolumn{9}{|l|}{ Gender } \\
\hline Female & $69,706(97.2)$ & $1,649(2.2)$ & $203(0.3)$ & $187(0.3)$ & & & & \\
\hline Male & & & & & $69,936(93.3)$ & $4,060(5.5)$ & $441(0.6)$ & $439(0.6)$ \\
\hline \multicolumn{9}{|l|}{ School type } \\
\hline Single sex & $24,326(98.0)$ & $423(1.8)$ & $41(0.1)$ & $26(0.1)$ & $22,975(93.7)$ & $1,213^{\dagger}(5.2)$ & $136+(0.5)$ & $148^{\dagger}(0.6)$ \\
\hline Coeducation & $45,380(96.7)$ & $1,226(2.5)$ & $162(0.4)$ & $161(0.4)$ & $46,961(93.2)$ & $2,847^{\dagger}(5.6)$ & $305+(0.6)$ & $291^{\dagger}(0.6)$ \\
\hline Grade Age & & & & & & & & \\
\hline 7 & $11,513(97.5)$ & $200(1.8)$ & $31(0.3)$ & $42(0.4)$ & $12,306(96.3)$ & $345(2.8)$ & $54(0.4)$ & $70(0.5)$ \\
\hline 8 & $11,646(98.4)$ & $136(1.1)$ & $35(0.3)$ & $25(0.2)$ & $12,224(96.5)$ & $293(2.3)$ & $72(0.6)$ & $66(0.5)$ \\
\hline$\leq 14$ years & 11,771 (98.0) & $161(1.3)$ & $32(0.3)$ & $31(0.3)$ & $12,278(96.0)$ & $341(2.7)$ & $75(0.6)$ & $80(0.7)$ \\
\hline 10 & $11,484(97.6)$ & $238(1.9)$ & $24(0.2)$ & $29(0.3)$ & $11,946(94.1)$ & $610(4.7)$ & $72(0.6)$ & $76(0.6)$ \\
\hline 11 & $11,897(96.4)$ & $400(3.0)$ & $38(0.3)$ & $29(0.3)$ & $10,659(90.5)$ & $998(8.1)$ & $80(0.7)$ & $79(0.7)$ \\
\hline$\leq 17$ years & 11,395 (95.2) & $514(4.2)$ & $43(0.3)$ & $31(0.3)$ & $10,523(87.0)$ & $1,473(11.8)$ & $88(0.6)$ & $68(0.6)$ \\
\hline \multicolumn{9}{|l|}{ Achivement } \\
\hline High & $6,577(96.7)$ & $112(1.6)$ & $38(0.7)$ & $54(1.0)$ & $8,491(93.2)$ & $404(4.6)$ & $77(0.9)$ & 109 (1.3) \\
\hline Mid-high & $16,997(98.0)$ & $309(1.7)$ & $34(0.2)$ & $22(0.2)$ & $16,507(95.3)$ & 645 (3.9) & $61(0.4)$ & $80(0.5)$ \\
\hline Middle & 19,716 (97.9) & $373(1.8)$ & $38(0.2)$ & $29(0.1)$ & $18,702(94.3)$ & $965(4.8)$ & $102(0.5)$ & $77(0.4)$ \\
\hline Mid-low & 18,087 (97.0) & $489(2.6)$ & $46(0.2)$ & $31(0.2)$ & $17,082(92.8)$ & $1,109(6.1)$ & $113(0.6)$ & $91(0.5)$ \\
\hline Low & $8,329(94.8)$ & $366(4.0)$ & $47(0.6)$ & $51(0.6)$ & $9,154(89.1)$ & $937(9.2)$ & $88(0.9)$ & $82(0.8)$ \\
\hline \multicolumn{9}{|l|}{ Economic } \\
\hline High & $3,282(94.0)$ & $94(2.8)$ & $34(1.3)$ & $58(1.9)$ & $5,856(89.4)$ & $439(7.7)$ & $76(1.1)$ & $112(1.8)$ \\
\hline Mid-high & $15,843(97.7)$ & $304(1.9)$ & $44(0.3)$ & $23(0.2)$ & $17,801(94.6)$ & $831(4.5)$ & $103(0.5)$ & $75(0.4)$ \\
\hline Middle & $35,054(98.0)$ & $654(1.7)$ & $57(0.1)$ & $51(0.2)$ & $31,754(94.6)$ & $1,526(4.5)$ & $135(0.4)$ & $147(0.5)$ \\
\hline Mid-low & 12,457 (96.6) & $390(2.9)$ & $34(0.3)$ & $23(0.2)$ & $11,215(92.6)$ & 784 (6.5) & $69(0.5)$ & $47(0.4)$ \\
\hline Low & $3,070(91.7)$ & $207(6.1)$ & $34(1.1)$ & $32(1.1)$ & $3,310(85.3)$ & $426(11.5)$ & $58(1.7)$ & $58(1.6)$ \\
\hline \multicolumn{9}{|l|}{ Family structure } \\
\hline Both parents & $56,894(97.8)$ & $1,090(1.8)$ & $99(0.2)$ & $107(0.2)$ & $57,563(94.2)$ & $2,919(4.8)$ & $278(0.5)$ & $305(0.5)$ \\
\hline Mother only & $7,350(96.1)$ & $264(3.3)$ & $31(0.4)$ & $15(0.2)$ & $6,204(91.1)$ & $504(7.5)$ & $57(0.8)$ & $35(0.6)$ \\
\hline Father only & $3,434(94.9)$ & $163(4.3)$ & $15(0.4)$ & $9(0.4)$ & 3,967 (89.9) & $356(8.5)$ & $35(0.9)$ & $30(0.8)$ \\
\hline Neither parent & $2,028(86.6)$ & $132(6.4)$ & $58(3.3)$ & $56(3.7)$ & 2,202 (81.9) & $281(11.6)$ & $71(3.3)$ & $69(3.2)$ \\
\hline \multicolumn{9}{|l|}{ Health risk behaviors } \\
\hline \multicolumn{9}{|l|}{ Smoking } \\
\hline No & $66,577(98.1)$ & $1,105(1.6)$ & $104(0.2)$ & $100(0.2)$ & $60,994(96.3)$ & $1,772(2.9)$ & $262(0.4)$ & $251(0.4)$ \\
\hline Yes & $3,129(80.7)$ & $544(13.7)$ & $99(2.8)$ & $87(2.8)$ & $8,942(77.0)$ & $2,288(19.8)$ & 179 (1.6) & $188(1.6)$ \\
\hline \multicolumn{9}{|l|}{ Drinking } \\
\hline No & $67,533(97.7)$ & $1,330(1.9)$ & $158(0.2)$ & $123(0.2)$ & $66,739(94.8)$ & $2,903(4.2)$ & $359(0.5)$ & $353(0.5)$ \\
\hline Yes & $2,173(82.8)$ & $319(12.2)$ & $45(2.0)$ & $64(3.1)$ & 3,197 (70.2) & $1,157(25.8)$ & $82(2.0)$ & $86(1.9)$ \\
\hline \multicolumn{9}{|l|}{ Obesity $^{a}$} \\
\hline No & $65,060(97.2)$ & $1,524(2.2)$ & $188(0.3)$ & $166(0.3)$ & $66,387(93.3)$ & $3,904(5.5)$ & $407(0.6)$ & $417(0.6)$ \\
\hline Yes & $4,646(96.7)$ & $125(2.5)$ & $15(0.3)$ & $21(0.5)$ & $3,549(94.4)$ & $156(4.1)$ & $34(0.8)$ & $22(0.7)$ \\
\hline
\end{tabular}


Table 1 Demographic characteristics by gender and the type of sexual intercourse experience: KYRBS (Continued)

\begin{tabular}{|c|c|c|c|c|c|c|c|c|}
\hline \multicolumn{9}{|c|}{ Health status ${ }^{\mathrm{b}}$} \\
\hline Good & $64,047(97.4)$ & $1,391(2.0)$ & $178(0.3)$ & $162(0.3)$ & $66,317(93.5)$ & $3,752(5.3)$ & $398(0.6)$ & $405(0.6)$ \\
\hline Poor & $5,659(94.9)$ & $258(4.2)$ & $25(0.4)$ & $25(0.6)$ & 3,619 (90.4) & 308 (7.6) & $43(1.1)$ & $34(1.0)$ \\
\hline \multicolumn{9}{|c|}{ STD diagnosis $^{c}$} \\
\hline No & $69,706(97.5)$ & $1,570(2.1)$ & $134(0.2)$ & $118(0.2)$ & $69,936(93.8)$ & $3,863(5.2)$ & $338(0.4)$ & $349(0.5)$ \\
\hline Yes & & 79 (33.5) & $69(32.5)$ & $69(34.0)$ & & $197(48.2)$ & $103(27.5)$ & $90(24.3)$ \\
\hline \multicolumn{9}{|l|}{ Violence $^{d}$} \\
\hline No & $68,529(97.6)$ & $1,498(2.1)$ & $111(0.2)$ & $107(0.2)$ & $67,156(94.1)$ & $3,591(5.1)$ & $307(0.4)$ & $302(0.4)$ \\
\hline Yes & $1,177(76.6)$ & $151(10.0)$ & $92(6.8)$ & $80(6.6)$ & $2,780(78.5)$ & 469 (13.4) & $134(4.1)$ & $137(4.0)$ \\
\hline
\end{tabular}

Notes: All the variables presented $P<0.001$, using a chi-square test, except ${ }^{\dagger} P>0.05$

‡Unweighted sample size and weighted percentage

${ }^{\text {a }}$ Perceived very obesity

${ }^{\mathrm{b}}$ Responses for subjective perception of health status

'Diagnosed with sexually transmitted diseases (STDs) including HIV Infection from sexual intercourse

dVictim of violence (being physically assaulted, threatened, or bullied)

among youths who had been victims of violence (all AOR range $=3-5$ for SROs) compared to youths who had not been victims of violence. When adjusted for the effects of the control variables (family structure, health risk behaviors, STDs, and violence), each SRO among youths with same- and both-sex intercourse tended to decrease. In particular, SROs among youths with same-sex and both-sex intercourse experience seemed to be strongly associated with STDs and violence. Our study demonstrated that after adjusting for the effect of STDs, violence, and associated factors, males with same-sex or both-sex intercourse experience had increased odds of all SROs when compared with opposite-sex intercourse only. However, females with same-sex and both-sex intercourse experience did not differ significantly in suicide planning and attempts. We detected that violence had strong associations with SROs of youths who had experienced same-sex or both-sex intercourse, with STDs including HIV infection (Table 3).

\section{Discussion}

We investigated the effects of the type of sexual intercourse among South Korean youths on suicide risk outcomes using Korea's representative KYRBS database. As seen in previous studies, we have confirmed that there is an association between having same-sex intercourse and SROs. In our study, $0.5 \%$ of youths in the 12th grade, aged 17 years old, reported having same-sex intercourse ( $0.6 \%$ of males and $0.3 \%$ of females), and $0.5 \%$ of those youths reported having intercourse experience with both-sexes ( $0.6 \%$ of males and $0.3 \%$ of females). Meanwhile, from 2001 to 2009, the median of youths in the United States for students in grades 9 to 12, aged 14-17 years old, was $2.5 \%$ for same-sex intercourse and $3.3 \%$ for intercourse with both-sexes [16]. The prevalence of same-sex intercourse among youths is lower in South
Korea than in western countries. However, the odds of each SRO of youths with same-sex intercourse experience were comparable between LGB youths in South Korea and in the west. Our results demonstrate that the prevalence for suicidal attempts were higher among youth with same-sex intercourse $(28.4 \%$ for females, $17.0 \%$ for males) and both-sex intercourse (34.1\% for females, $16.8 \%$ for males) experience than those with opposite-sex intercourse $(18.0 \%$ for females, $7.4 \%$ for males) experience. The odds ratios [OR] among males with same-sex intercourse experience were 1.6 for suicidal ideation, 2.3 for plans for suicide, and 2.5 for suicidal attempts. These findings correspond to the previous meta-analytic review in the west, which reported that the risk of suicide among LGB youths was 2.9 times higher than in heterosexual youths [4, 13, 17]. In adjusted analyses, males with same- or both-sex intercourse experiences were higher in SROs compared with males who had only experienced opposite-sex intercourse. Many studies have reported higher rates of SROs among gay males when compared to lesbian females $[3,18,19]$. Based on our study, we were able to confirm that violence is a risk factor for suicide among youths with same- or both-sex intercourse. Our study shows that youths with same- or both-sex intercourse experience is far higher when combined with victims from violence. These findings are consistent with prior studies that highlight the link between homophobia and masculinity in the lives of adolescent boys. In previous studies, more than half of the gay youths surveyed reported having been verbally humiliated by their peers [20] and about 30\% reported having been physically assaulted [21]. One-third of LGB youths have reported experiencing verbal abuse from their families, and $1 / 4$ have reported being physically bullied by their peers. That is, the prevalence of victims of violence of LGB youths is similar in Asian countries when compared 
Table 2 Prevalence of suicide risk outcomes by the type of sexual intercourse experience: KYRBS

\begin{tabular}{|c|c|c|c|c|c|c|}
\hline \multirow{3}{*}{$\begin{array}{l}\text { Merged } 2012 \sim 2013 \\
n=146,621 \\
\text { Characteristics }\end{array}$} & \multicolumn{6}{|c|}{ Suicide risk outcomes, Responses 'Yes' $=$ No. $(\%)^{\ddagger}$} \\
\hline & \multicolumn{3}{|c|}{ Females, $n=71,745$} & \multicolumn{3}{|l|}{ Males, $n=74,876$} \\
\hline & Suicide ideation & Suicide plan & Suicide attempt & Suicide ideation & Suicide plan & Suicide attempt \\
\hline Yes $=$ No. $(\%)^{\ddagger}$ & $15,603(21.7)$ & $5,240(7.2)$ & $3,912(5.5)$ & $10,102(13.6)$ & $3,637(4.8)$ & $2,127(2.8)$ \\
\hline \multicolumn{7}{|l|}{ Sexual intercourse } \\
\hline No contact & $14,726(21.0)$ & $4,787(6.8)$ & $3,494(5.0)$ & $8,838(12.7)$ & $3,003(4.3)$ & $1,678(2.4)$ \\
\hline Opposite sex & $694(42.2)$ & $308(18.7)$ & $297(18.0)$ & $973(23.8)$ & $446(10.9)$ & $306(7.4)$ \\
\hline Same sex & $92(45.9)$ & $74(34.3)$ & $57(28.4)$ & $147(33.7)$ & $93(22.0)$ & $73(17.0)$ \\
\hline Both sexes & $91(49.4)$ & $71(41.2)$ & $64(34.1)$ & $144(34.2)$ & 95 (21.6) & 70 (16.8) \\
\hline \multicolumn{7}{|l|}{ Socioeconomic factors } \\
\hline \multicolumn{7}{|l|}{ School type } \\
\hline Single sex & $5,052(20.3)$ & $1,550(6.2)$ & $1,084(4.4)$ & $3,219^{\dagger}(13.2)$ & $1,063(4.3)$ & $587(2.4)$ \\
\hline Coeducation & $10,551(22.4)$ & $3,690(7.8)$ & $2,828(6.1)$ & $6,883^{\dagger}(13.8)$ & $2,574(5.1)$ & $1,540(3.0)$ \\
\hline Grade & & & & & & \\
\hline 7 & $2,615(22.4)$ & $1,049(9.0)$ & $823(7.3)$ & 1,553 (12.6) & $611(5.0)$ & $328(2.6)$ \\
\hline 8 & 2,852 (24.2) & $1,128(9.5)$ & $849(7.4)$ & $1,710(13.7)$ & $704(5.5)$ & $427(3.4)$ \\
\hline$\leq 12$ years & $2,698(22.3)$ & $975(8.1)$ & $714(6.0)$ & $1,804(14.4)$ & $679(5.5)$ & $408(3.2)$ \\
\hline 10 & $2,502(21.1)$ & $719(6.1)$ & $576(4.8)$ & $1,742(13.3)$ & $600(4.5)$ & $386(2.9)$ \\
\hline 11 & $2,685(21.4)$ & $802(6.4)$ & $553(4.3)$ & $1,689(14.1)$ & $545(4.5)$ & $295(2.5)$ \\
\hline$\leq 17$ years & $2,251(18.7)$ & $567(4.6)$ & $397(3.3)$ & $1,604(13.3)$ & $498(4.1)$ & $283(2.3)$ \\
\hline \multicolumn{7}{|l|}{ Achivement } \\
\hline High & 1,235 (17.9) & $391(5.8)$ & $258(4.0)$ & $1,109(12.9)$ & $441(5.0)$ & $265(3.0)$ \\
\hline Mid-high & $3,239(18.7)$ & $1,058(6.2)$ & $693(4.1)$ & $2,038(11.8)$ & $712(4.0)$ & $404(2.3)$ \\
\hline Middle & $3,760(18.6)$ & $1,155(5.6)$ & $831(4.1)$ & $2,439(12.3)$ & $821(4.1)$ & $438(2.2)$ \\
\hline Mid-low & $4,586(24.4)$ & $1,544(8.2)$ & $1,208(6.4)$ & $2,655(14.8)$ & $924(5.1)$ & $500(2.6)$ \\
\hline Low & $2,783(32.0)$ & $1,092(12.4)$ & $922(10.5)$ & $1,861(18.2)$ & $739(7.3)$ & $520(5.1)$ \\
\hline \multicolumn{7}{|l|}{ Economic } \\
\hline High & $734(21.3)$ & $310(9.3)$ & $226(7.0)$ & $945(14.5)$ & $467(7.3)$ & $308(4.7)$ \\
\hline Mid-high & $3,069(19.0)$ & $1,033(6.3)$ & $759(4.7)$ & $2,223(12.0)$ & $771(4.2)$ & $425(2.2)$ \\
\hline Middle & 6,937 (19.2) & $2,227(6.1)$ & $1,648(4.6)$ & 3,894 (11.7) & 1,329 (3.9) & $737(2.2)$ \\
\hline Mid-low & $3,533(27.5)$ & 1,115 (8.6) & $841(6.5)$ & $2,053(17.0)$ & $619(5.0)$ & $368(2.9)$ \\
\hline Low & $1,330(40.3)$ & $555(17.3)$ & $438(13.6)$ & $987(25.9)$ & $451(11.8)$ & $289(7.5)$ \\
\hline \multicolumn{7}{|l|}{ Family structure } \\
\hline Both parents & $11,771(20.1)$ & $3,751(6.4)$ & $2,764(4.8)$ & $7,788(12.9)$ & $2,733(4.5)$ & $1,535(2.5)$ \\
\hline Mother only & $2,020(26.7)$ & $738(9.9)$ & $543(7.3)$ & $1,031(15.1)$ & $362(5.2)$ & $225(3.2)$ \\
\hline Father only & $1,051(29.4)$ & $401(11.0)$ & $325(9.1)$ & 739 (16.8) & $278(6.2)$ & $167(3.6)$ \\
\hline Neither parent & 761 (35.6) & $350(17.0)$ & $280(13.9)$ & $544(22.0)$ & $264(11.1)$ & $200(8.4)$ \\
\hline \multicolumn{7}{|l|}{ Health risk behaviors } \\
\hline \multicolumn{7}{|l|}{ Smoking } \\
\hline No & $13,750(20.2)$ & $4,366(6.4)$ & $3,114(4.6)$ & $7,509(12.0)$ & $2,579(4.1)$ & $1,370(2.2)$ \\
\hline Yes & $1,853(47.9)$ & $874(23.1)$ & $798(20.9)$ & 2,593 (22.4) & $1,058(9.1)$ & $757(6.4)$ \\
\hline \multicolumn{7}{|l|}{ Drinking } \\
\hline No & $14,329(20.7)$ & $4,598(6.6)$ & $3,347(4.9)$ & $8,798(12.6)$ & $3,053(4.3)$ & $1,701(2.4)$ \\
\hline Yes & $1,274(49.3)$ & $642(25.2)$ & $565(21.8)$ & $1,304(29.0)$ & 584 (13.2) & $426(9.7)$ \\
\hline
\end{tabular}


Table 2 Prevalence of suicide risk outcomes by the type of sexual intercourse experience: KYRBS (Continued)

\begin{tabular}{|c|c|c|c|c|c|c|}
\hline \multicolumn{7}{|l|}{ Obesity $^{a}$} \\
\hline No & $14,162(21.1)$ & $4,684(6.9)$ & $3,520(5.3)$ & $9,408(13.3)$ & $3,357(4.7)$ & $1,958(2.7)$ \\
\hline Yes & $1,441(30.1)$ & $556(11.5)$ & 392 (8.3) & 694 (18.8) & $280(7.5)$ & $169(4.4)$ \\
\hline \multicolumn{7}{|c|}{ Health status ${ }^{b}$} \\
\hline Good & $13,162(19.9)$ & $4,246(6.4)$ & $3,178(4.9)$ & $8,902(12.6)$ & $3,137(4.4)$ & $1,816(2.5)$ \\
\hline Poor & $2,441(40.7)$ & 994 (16.9) & 734 (12.5) & $1,200(30.9)$ & $500(13.1)$ & $311(7.9)$ \\
\hline \multicolumn{7}{|c|}{ STD diagnosis ${ }^{c}$} \\
\hline No & $15,476(21.5)$ & $5,147(7.1)$ & $3,824(5.4)$ & $9,935(13.4)$ & $3,511(4.7)$ & $2,032(2.7)$ \\
\hline Yes & $127(61.2)$ & $93(44.4)$ & $88(42.8)$ & 167 (44.6) & $126(34.5)$ & $95(24.7)$ \\
\hline \multicolumn{7}{|c|}{ Violence $^{d}$} \\
\hline No & $14,765(20.9)$ & $4,748(6.7)$ & $3,481(5.0)$ & $8,877(12.5)$ & $2,897(4.0)$ & $1,593(2.2)$ \\
\hline Yes & 838 (55.3) & 492 (32.8) & 431 (28.7) & 1,225 & 740 (21.6) & $534(15.6)$ \\
\hline
\end{tabular}

Notes: All the variables presented $P \leq 0.001$, using a chi-square test, except ${ }^{\dagger} P>0.05$

${ }^{\ddagger}$ Unweighted sample size and weighted percentage

Outcome variable (suicide risk outcomes) $=$ binary variable Yes or No

aPerceived very obesity

${ }^{\mathrm{b}}$ Responses for subjective perception of health status

'Diagnosed with sexually transmitted diseases (STDs) including HIV Infection from sexual intercourse

${ }^{d}$ Victim of violence (being physically assaulted, threatened, or bullied)

to western countries [8, 22]. It has been suggested that LGB youths hide their concerns about sexual orientation, feelings of isolation or helplessness, and stigmatization. This results in higher levels of stress in LGB youths than in heterosexual youths in a society that is full of negativity and discrimination towards homosexuals [13, 23-25]. In Asian society, homosexuality has been considered unnatural for ages. A social atmosphere of condemning and forbidding homosexuality has been established, leading to a stigmatization of homosexuality as a pathological disorder. In the current study, LGB youths living in Asian cities received little support from their friends, and commonly experienced teasing or were treated unfairly $[22,26]$. One can imagine the difficulties that Korean LGBs may experience with such social prejudice against homosexuality. These difficulties isolate LGB youths and bring about conflict, thereby leading to violence and depression that can increase the risk of suicide [26]. Given that some LGB youths have been victims of violence, LGB youths can be considered a high-risk group for suicide [24, 27]. The results suggest that the prevention of victimization among LGB youths can decrease hopelessness and depression, perhaps leading to less suicidal attempts $[7,23]$. Our results suggest that supportive and inclusive social environments for sexual orientation may lower the risk of suicide attempts among LGB youths [28, 29]. Creating policies of preventing school violence, including bullying in particular, is one of the most important protection factors for LGB youths
$[28,30]$. Recent research has shown that higher levels of protectiveness and supportive school climates for LGB youths reduced suicidal thoughts of LGB youths, even after controlling for confounding variables [29]. Moreover, parental support has been reported to affect the health and well-being of LGB youths [31, 32]. Health risk behaviors and subjective perception of an individual's own health, including depression, have been shown to be negative among LGB youths who lack parental support $[15,23,31,33]$. Also, in order to decrease SROs among youths there is a need to improve the negative impression and attitude that society displays towards homosexuals, and a need to establish anti-bullying policies towards LGB youths $[28,34]$. On the same note, family-based interventions can decrease hopelessness and depression, thereby leading to less suicide attempts [35]. Countries are obligated to establish policies that reinforce the family's role to ensure parental love and support towards children and youths [2]. This reinforcement can help create a social atmosphere that allows understanding and is receptive towards an individual's own sexual identity and that of others. SROs among youths with same- and both-sex intercourse experience seemed to be strongly associated with exposure to violence and sexual health risk. These results may be used for programs that prevent suicide as a result of issues related to intercourse in youths and national policies that will make accessible social support systems for LGB youths. Our findings of elevated levels of SROs, STDs (including HIV infection), and being a victim of violence and/or hopelessness in youths with same- and both-sex intercourse 
Table 3 Associations between the type of sexual intercourse and suicide risk outcomes: KYRBS

\begin{tabular}{|c|c|c|c|c|c|c|}
\hline \multirow{2}{*}{$\begin{array}{l}\text { Merged } \\
2012 \sim 2013 \\
n=146,621^{\ddagger}\end{array}$} & \multicolumn{2}{|l|}{$\begin{array}{l}\text { Suicide ideation, } \\
\text { OR ( } 95 \% \text { Cls) }\end{array}$} & \multicolumn{2}{|l|}{$\begin{array}{l}\text { Suicide plan, } \\
\text { OR ( } 95 \% \text { Cls) }\end{array}$} & \multicolumn{2}{|l|}{$\begin{array}{l}\text { Suicide attempt, } \\
\text { OR }(95 \% \text { Cls })\end{array}$} \\
\hline & Unadjusted & Adjusted & Unadjusted & Adjusted & Unadjusted & Adjusted \\
\hline \multicolumn{7}{|l|}{ Female } \\
\hline \multicolumn{7}{|l|}{ Sexual intercourse } \\
\hline Opposite sex & .00 & 1.00 & 1.00 & 1.00 & 1.00 & 1.00 \\
\hline Same sex & $1.16^{\dagger}(0.88-1.53)$ & $0.59 *(0.42-0.83)$ & $2.27(1.66-3.09)$ & $1.19^{\dagger}(0.82-1.73)$ & $1.81(1.29-2.52)$ & $0.76^{\dagger}(0.52-1.12)$ \\
\hline Both sexes & $1.33^{\dagger}(0.98-1.81)$ & $0.63^{*}(0.43-0.92)$ & $3.06(2.18-4.28)$ & $1.50^{\dagger}(0.99-2.26)$ & $2.36(1.67-3.33)$ & $0.88^{\dagger}(0.53-1.45)$ \\
\hline No contact & $0.36(0.33-0.40)$ & $0.62(0.55-0.70)$ & $0.31(0.36-0.41)$ & $0.66(0.56-0.77)$ & $0.24(0.30-0.36)$ & $0.54(0.46-0.64)$ \\
\hline \multicolumn{7}{|l|}{ Family structure } \\
\hline Both parents & 1.00 & 1.00 & 1.00 & 1.00 & 1.00 & 1.00 \\
\hline Mother only & $1.44(1.37-1.51)$ & $1.28(1.22-1.36)$ & $1.60(1.48-1.73)$ & $1.38(1.27-1.50)$ & $1.57^{*}(1.43-1.71)$ & $1.32(1.20-1.45)$ \\
\hline Father only & $1.65(1.53-1.78)$ & $1.39(1.29-1.51)$ & $1.82(1.64-2.02)$ & $1.44(1.29-1.61)$ & $2.00(1.78-2.25)$ & $1.54(1.35-1.75)$ \\
\hline Neither parent & $2.19(2.00-2.40)$ & $1.47(1.33-1.64)$ & $3.01(2.67-3.39)$ & $1.55(1.34-1.79)$ & $3.20(2.80-3.67)$ & $1.47(1.24-1.73)$ \\
\hline \multicolumn{7}{|c|}{ Health risk behavior } \\
\hline Smoking & $3.62(3.39-3.85)$ & $2.34(2.18-2.51)$ & $4.41(4.07-4.79)$ & $2.34(2.11-2.59)$ & $5.45(5.00-5.95)$ & $2.77(2.50-3.09)$ \\
\hline Drinking & $3.73(3.46-4.02)$ & $2.20(2.01-2.40)$ & $4.78(4.37-5.24)$ & $2.39(2.13-2.67)$ & $5.42(4.92-5.96)$ & $2.41(2.14-2.71)$ \\
\hline Obesity $^{a}$ & $1.61(1.51-1.71)$ & $1.43(1.34-1.53)$ & $1.74(1.59-1.91)$ & $1.48(1.34-1.64)$ & $1.61(1.45-1.78)$ & $1.35(1.21-1.52)$ \\
\hline Health status ${ }^{b}$ & $2.74(2.60-2.89)$ & $2.42(2.29-2.55)$ & $2.97(2.77-3.19)$ & $2.45(2.27-2.65)$ & $2.78(2.57-3.01)$ & $2.23(2.04-2.43)$ \\
\hline STD diagnosis $^{c}$ & $5.74(4.42-7.44)$ & $0.94^{\dagger}(0.66-1.34)$ & $10.43(7.88-13.79)$ & $0.81^{\dagger}(0.56-1.17)$ & $13.22(9.83-17.79)$ & $1.06^{\dagger}(0.71-1.58)$ \\
\hline Violence $^{d}$ & $4.66(4.22-5.14)$ & $3.17(2.83-3.56)$ & $6.82(6.11-7.61)$ & $3.87(3.39-4.43)$ & $7.65(6.82-8.59)$ & $4.10(3.55-4.72)$ \\
\hline \multicolumn{7}{|l|}{ Male } \\
\hline \multicolumn{7}{|l|}{ Sexual intercourse } \\
\hline Opposite sex & 1.00 & 1.00 & 1.00 & 1.00 & 1.00 & 1.00 \\
\hline Same sex & $1.62(1.31-2.01)$ & $1.29 *(1.01-1.64)$ & $2.30(1.80-2.93)$ & $1.45^{*}(1.10-1.92)$ & $2.58(1.95-3.40)$ & $1.69^{*}(1.22-2.35)$ \\
\hline Both sexes & $1.66(1.35-2.03)$ & $1.43(1.16-1.78)$ & $2.23(1.74-2.88)$ & $1.57^{*}(1.19-2.07)$ & $2.54(1.92-3.37)$ & $1.84(1.32-2.56)$ \\
\hline No contact & $0.36(0.33-0.40)$ & $0.76(0.70-0.83)$ & $0.36(0.32-0.40)$ & $0.67(0.60-0.76)$ & $0.30(0.26-0.34)$ & $0.67(0.58-0.78)$ \\
\hline \multicolumn{7}{|l|}{ Family structure } \\
\hline Both parents & 1.00 & 1.00 & 1.00 & 1.00 & 1.00 & 1.00 \\
\hline Mother only & $1.19(1.11-1.28)$ & $1.08(1.00-1.16)$ & $1.16(1.04-1.29)$ & $1.02^{\dagger}(0.90-1.14)$ & $1.30(1.12-1.50)$ & $1.10^{\dagger}(0.94-1.28)$ \\
\hline Father only & $1.36(1.25-1.48)$ & $1.16(1.06-1.26)$ & $1.39(1.23-1.58)$ & $1.11^{\dagger}(0.97-1.27)$ & $1.45(1.23-1.71)$ & $1.08^{\dagger}(0.91-1.30)$ \\
\hline Neither parent & $1.90(1.72-2.09)$ & $1.27(1.15-1.42)$ & $2.66(2.32-3.03)$ & $1.37(1.19-1.58)$ & $3.55(3.04-4.14)$ & $1.61(1.32-1.92)$ \\
\hline \multicolumn{7}{|c|}{ Health risk behavior } \\
\hline Smoking & $2.11(2.01-2.23)$ & $1.56(1.47-1.66)$ & $2.35(2.19-2.53)$ & $1.49(1.36-1.63)$ & $3.11(2.84-3.41)$ & $1.81(1.62-2.02)$ \\
\hline Drinking & $2.83(2.64-3.02)$ & $1.82(1.68-1.96)$ & $3.38(3.06-3.73)$ & $1.94(1.72-2.18)$ & $4.41(3.97-4.89)$ & $2.19(1.92-2.50)$ \\
\hline Obesity $^{a}$ & $1.51(1.39-1.64)$ & $1.24(1.13-1.35)$ & $1.64(1.45-1.86)$ & $1.26(1.10-1.44)$ & $1.64(1.40-1.93)$ & $1.22^{*}(1.03-1.46)$ \\
\hline Health status ${ }^{b}$ & $3.08(2.88-3.30)$ & $2.74(2.56-2.95)$ & $3.28(2.96-3.63)$ & $2.73(2.44-3.05)$ & $3.30(2.91-3.74)$ & $2.56(2.23-2.93)$ \\
\hline STD diagnosis $^{c}$ & $5.19(4.32-6.25)$ & $1.35^{*}(1.10-1.66)$ & $10.71(8.69-13.20)$ & $1.80(1.40-2.32)$ & $11.86(9.47-14.84)$ & $1.34^{*}(1.02-1.76)$ \\
\hline Violence $^{d}$ & $3.78(3.53-4.04)$ & $3.02(2.81-3.24)$ & $6.55(6.01-7.13)$ & $4.77(4.35-5.23)$ & $8.22(7.40-9.14)$ & $5.56(4.97-6.22)$ \\
\hline
\end{tabular}

Notes: All the variables presented $P \leq 0.001$, using simple and multiple logistic regression analysis, except ${ }^{*} P<0.05 ;{ }^{\dagger} P>0.05$

$\mathrm{OR}=$ odds ratio; $\mathrm{Cls}=$ Confidence Intervals

Outcome variable: Suicide risk outcomes $=$ Yes (Reference group; Suicide risk outcomes $=$ No)

${ }^{\ddagger}$ Unweighted sample size

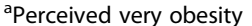

berception of health status were quite poor or poor

'Diagnosed with sexually transmitted diseases (STDs) including HIV Infection from sexual intercourse

dVictim of violence (being physically assaulted, threatened, or bullied) 
experience, provide a public health rationale for implementing safe school programs designed to prevent violence. Awareness of the relationship between these variables and being LGB is especially important for school health programs that are funded by STD (including HIV) funding streams $[13,36]$. The efforts of school health departments to reduce STD-related health risk behaviors must be implemented to decrease rates of SROs. Youths with same- and both-sex intercourse experience have a higher association with the risk of suicide than youths with opposite-sex intercourse experience. It is necessary to implement prevention programs for suicide as a result of sexual intercourse in youths and establish social support systems. Additionally, educational departments should instill acceptance of diversity and respect towards life into school systems. Schools should consider integrating specific content about LGB health risks and health disparities in training regarding violence, STDs (including HIV infection), and suicide prevention. For too many LGB and gender variant students, school violence has resulted in school failure and restricted life chances that limit vocational opportunities and undermine the victim's human potential. Therefore, school educators must continue to advocate for these youths and implement LGB inclusive policies and programs in order to promote safe and supportive learning environments where all students are protected from sexual risk behavior. Our results serve as fundamental data demonstrating that intercourse in youths contributes to the risk of suicide. As such, this data may be used for suicide as a result of issues related to sexual intercourse prevention programs, national policies that will make accessible social support systems for LGB youths, and for comparison data on sexual behaviors among youths in Korea and other countries.

\section{Strengths and limitations of the study}

Strengths of our study were that we were able to minimize selection bias by using a representative sampling of middle and high school students nationwide. In addition, our database included a sample size of 146,621 students, which is a large enough population. Finally, the KYRBS questionnaire used in our study demonstrated high consistency and reproducibility by showing a comparable trend of results annually. Limitations of our study should also be noted. First, our study was a crosssectional study; therefore, a temporal relationship cannot be established between type of sexual intercourse and SROs. Future longitudinal research is needed in order to further investigate the major risk factors for suicide. Second, limitations of our study include analyzing the association between type of sexual intercourse and SROs among youths without any self-reported information on sexual orientation. This made us unable to demonstrate the prevalence of LGB youths in South Korea. In addition, we regarded youths with same-sex or both-sex intercourse experience as lesbian, gay, or bisexual. This was because we could not get information about sexual orientation on the basis of sexual identity and sexual attraction. However, in other research, the pattern of risk factors significantly associated with SROs among youths was nearly the same for type of sexual intercourse experience as it was for sexual identity [3]. Therefore, future research should use a combination of information on sexual orientation and type of sexual intercourse experience as predictors of SROs. In addition, we were not able collect information about the frequency of sexual intercourse. Future research is needed in order to determine the relation between the frequency of sexual intercourse and SROs. Third, we did not control for social factors, such as school climate or connectedness, which may have negative psychological effects on LGB youths [29]. These measures were not collected or were unavailable. LGB youths may respond to school climate in unhealthy ways (sexual risk behavior and alcohol, tobacco use) or isolate themselves. Finally, various risk factors (violence, hopelessness, health risk behavior) included in our analyses may mediate the associations between type of sexual intercourse experience and SROs. However, we cannot strictly test a major risk factor in our study because we do not know the time sequences of those risk factors in relation to the timing of type of sexual intercourse experience and SROs.

\section{Conclusions}

Compared to youths with experience of opposite-sex intercourse, youths with same- and both-sex intercourse experience were higher in all ORs of outcomes for the suicide risk than youths with only opposite-sex intercourse experience. Youths with sexual intercourse experience showed a higher association with outcomes for the suicide risk than youths who had no intercourse experience. In the multiple logistic regression analysis, after adjusting for family structure, health risk behaviors, STDs (including HIV infection), and violence, males with same-sex or both-sex intercourse experience were higher in their odds of SROs compared with males with opposite-sex intercourse experience only. We detected that SROs in youths with same-sex or both-sex intercourse experience had strong associations with gender (males), violence, and STDs. This study provides evidence that SROs for LGB youths are related to violence and STDs, controlling for risk factors. Therefore, school educators must continue to advocate for these youths and implement LGB inclusive policies and programs in order to promote safe and supportive learning environments where all students are protected from health risk behavior. 


\section{Abbreviations}

AOR: Adjusted odds ratio; Cl: Confidence interval; KYRBS: Korea youth risk behavior web-based survey; LGB: Lesbian, gay, or bisexual; OR: Odds ratio; SROs: Suicide risk outcomes; STDs: Sexually transmitted diseases

\section{Acknowledgements}

None.

\section{Funding}

We did not receive any funding or support.

\section{Availability of data and materials}

All data included in this research is accessible. This research made use of Korea Youth Risk Behavior Web-based Survey (KYRBS) database (http://cdc.go.kr/CDC/ contents/CdcKrContentView.jsp?cid=68353\&menulds=HOME001-MNU1130MNU2393-MNU2394-MNU2399). KYRBS was approved by the Ministry of Education, Ministry of Health and Welfare, Korea Centers for Disease Control and Prevention (Grant No. 11758).

\section{Consent for publication}

\section{Not applicable.}

\section{Ethics approval and consent to participate}

No institutional review board approval was required because no human participants were involved in this study.

\section{Authors' contributions}

GHK contributed to the concept and design of the study, the writing of the manuscript, and the analysis, interpreting of the data for the work. HSA contributed to the concept and design of the study, drafting the work or revising it critically for important intellectual content, read and approved the final manuscript. HJK contributed giving final approval of the version to be published. All authors read and approved the final manuscript.

\section{Competing interests}

The authors declare that they have no competing interests.

\section{Author details}

${ }^{1}$ Department of School Health Education, Sanggye High School, 432, Nohaero, Nowon-gu, Seoul 01761, Korea. ${ }^{2}$ Department of Preventive Medicine, College of Medicine, Korea University, 73, Inchon-ro, Seongbuk-gu, Seoul 02841, Korea.

\section{Received: 3 May 2016 Accepted: 30 November 2016} Published online: 07 December 2016

\section{References}

1. Lee GY, Choi YJ. Association of school, family, and mental health characteristics with suicidal ideation among Korean adolescents. Res Nurs Health. 2015;38(4):301-10.

2. Peltzer K, Pengpid S. Suicidal ideation and associated factors among school-going adolescents in Thailand. Int J Environ Res Public Health. 2012;9(2):462-73.

3. Stone DM, Luo F, Ouyang L, Lippy C, Hertz MF, Crosby AE. Sexual orientation and suicide ideation, plans, attempts, and medically serious attempts: evidence from local Youth Risk Behavior Surveys, 2001-2009. Am J Public Health. 2014; 104(2):262-71.

4. Marshal MP, Dietz $\sqcup$, Friedman MS, Stall R, Smith HA, McGinley J, et al. Suicidality and depression disparities between sexual minority and heterosexual youth: a meta-analytic review. J Adolesc Health. 2011;49(2):115-23.

5. Duncan DT, Hatzenbuehler ML. Lesbian, gay, bisexual, and transgender hate crimes and suicidality among a population-based sample of sexual-minority adolescents in Boston. Am J Public Health. 2014;104(2):272-8.

6. Jiang Y, Perry DK, Hesser JE. Adolescent suicide and health risk behaviors: Rhode Island's 2007 Youth Risk Behavior Survey. Am J Prev Med. 2010; 38(5):551-5.

7. Liu RT, Mustanski B. Suicidal ideation and self-harm in lesbian, gay, bisexual, and transgender youth. Am J Prev Med. 2012;42(3):221-8.

8. Lian Q, Zuo X, Lou C, Gao E, Cheng Y. Sexual orientation and risk factors for suicidal ideation and suicide attempts: a multi-centre cross-sectional study in three Asian cities. J Epidemiol. 2015;25(2):155-61.
9. Korea Centers for Disease Control and Prevention: Korea Youth Risk Behavior Web-basedSurvey Use guidelines. [http://cdc.go.kr/CDC/contents/ CdcKrContentView.jsp?cid=68353\&menulds=HOME001-MNU1130-MNU2393MNU2394-MNU2399]. Accessed 9 Jan 2016.

10. Swahn MH, Reynolds MR, Tice M, Miranda-Pierangeli MC, Jones $C R$, Jones $I R$. Perceived overweight, BMI, and risk for suicide attempts: findings from the 2007 Youth Risk Behavior Survey. J Adolesc Health. 2009;45(3):292-5.

11. Eaton DK, Lowry R, Brener ND, Kann L, Romero L, Wechsler H. Trends in Human Immunodeficiency Virus- and Sexually Transmitted Disease-Related Risk Behaviors Among US High School Students, 1991-2009. Am J Prev Med. 2011:40(4):427-33.

12. Blosnich JR, Bossarte RM, Silenzio VM. Suicidal ideation among sexual minority veterans: results from the 2005-2010 Massachusetts Behavioral Risk Factor Surveillance Survey. Am J Public Health. 2012;102 Suppl 1:S44-7.

13. Russell ST, Ryan C, Toomey RB, Diaz RM, Sanchez J. Lesbian, gay, bisexual, and transgender adolescent school victimization: implications for young adult health and adjustment. J Sch Health. 2011;81(5):223-30.

14. Millett GA, Peterson JL. The known hidden epidemic HIV/AIDS among black men who have sex with men in the United States. Am J Prev Med. 2007; 32(4 Suppl):S31-3.

15. van Bergen DD, Bos HM, van Lisdonk J, Keuzenkamp S, Sandfort TG. Victimization and suicidality among Dutch lesbian, gay, and bisexual youths. Am J Public Health. 2013;103(1):70-2

16. Kann L, Olsen EO, McManus T, Kinchen S, Chyen D, Harris WA, et al. Sexual identity, sex of sexual contacts, and health-risk behaviors among students in grades 9-12-youth risk behavior surveillance, selected sites, United States, 20012009. [https://www.cdc.gov/mmwr/pdf/ss/ss60e0606.pdf]. Accessed 2 Apr 2016.

17. Garofalo R, Wolf RC, Wissow LS, Woods ER, Goodman E. Sexual orientation and risk of suicide attempts among a representative sample of youth. Arch Pediatr Adolesc Med. 1999;153(5):487-93.

18. Wang J, Ploderl M, Hausermann M, Weiss MG. Understanding Suicide Attempts Among Gay Men From Their Self-perceived Causes. J Nerv Ment Dis. 2015;203(7):499-506

19. Wang J, Hausermann M, Berrut S, Weiss MG. The impact of a depression awareness campaign on mental health literacy and mental morbidity among gay men. J Affect Disord. 2013;150(2):306-12.

20. Hoyt D'Anna L, Nguyen HH, Reynolds GL, Fisher DG, Janson M, Chen C, et al. The Relationship between Sexual Minority Verbal Harassment And Utilization of Health Services: Results from Countywide Risk Assessment Survey (CRAS) 2004. J Gay Lesbian Soc Serv. 2012;24(2):119-39.

21. Russell ST, Joyner K. Adolescent sexual orientation and suicide risk: evidence from a national study. Am J Public Health. 2001:91(8):1276-81.

22. Hu X, Wang Y. LGB identity among young Chinese: the influence of traditional culture. J Homosex. 2013;60(5):667-84.

23. Mustanski B, Liu RT. A longitudinal study of predictors of suicide attempts among lesbian, gay, bisexual, and transgender youth. Arch Sex Behav. 2013; 42(3):437-48.

24. Shields JP, Whitaker K, Glassman J, Franks HM, Howard K. Impact of victimization on risk of suicide among lesbian, gay, and bisexual high school students in San Francisco. J Adolesc Health. 2012;50(4):418-20.

25. Hatzenbuehler ML. How does sexual minority stigma "get under the skin"? A psychological mediation framework. Psychol Bull. 2009;135(5):707-30.

26. Yoon JH, So WY. Differences in Lifestyles Including Physical Activity According to Sexual Orientation among Korean Adolescents. [https:// www.ncbi.n/m.nih.gov/pmc/articles/PMC4441931/]. Accessed 1 Mar 2015.

27. Haas AP, Eliason M, Mays VM, Mathy RM, Cochran SD, D'Augelli AR, et al. Suicide and suicide risk in lesbian, gay, bisexual, and transgender populations: review and recommendations. J Homosex. 2011;58(1):10-51.

28. Hatzenbuehler ML, Keyes KM. Inclusive anti-bullying policies and reduced risk of suicide attempts in lesbian and gay youth. J Adolesc Health. 2013; 53(1 Suppl):S21-6.

29. Hatzenbuehler ML, Birkett M, Van Wagenen A, Meyer IH. Protective school climates and reduced risk for suicide ideation in sexual minorityyouths. Am J Public Health. 2014;104(2):279-86.

30. Green JG, Johnson RM, Dunn EC, Lindsey M, Xuan Z, Zaslavsky AM. Mental health service use among high school students exposed to interpersonal violence. J Sch Health. 2014;84(2):141-9.

31. Bouris A, Guilamo-Ramos V, Pickard A, Shiu C, Loosier PS, Dittus P, et al. A systematic review of parental influences on the health and well-being of lesbian, gay, and bisexual youth: time for a new public health research and practice agenda. J Prim Prev. 2010;31(5-6):273-309. 
32. Rice E, Petering R, Rhoades H, Barman-Adhikari A, Winetrobe H, Plant A, et al. Homelessness and Sexual Identity Among Middle School Students. J Sch Health. 2015;85(8):552-7.

33. Rothman EF, Sullivan M, Keyes S, Boehmer U. Parents' supportive reactions to sexual orientation disclosure associated with better health: results from a population-based survey of LGB adults in Massachusetts. J Homosex. 2012; 59(2):186-200

34. Mahdi I, Jevertson J, Schrader R, Nelson A, Ramos MM. Survey of new Mexico school health professionals regarding preparedness to support sexual minority students. J Sch Health. 2014;84(1):18-24.

35. Ploderl M, Wagenmakers EJ, Tremblay P, Ramsay R, Kralovec K, Fartacek C, et al. Suicide risk and sexual orientation: a critical review. Arch Sex Behav. 2013;42(5):715-27.

36. Eaton DK, Lowry R, Brener ND, Galuska DA, Crosby AE. Associations of body mass index and perceived weight with suicide ideation and suicide attempts among US high school students. Arch Pediatr Adolesc Med. 2005;159(6):513-9.

Submit your next manuscript to BioMed Central and we will help you at every step:

- We accept pre-submission inquiries

- Our selector tool helps you to find the most relevant journal

- We provide round the clock customer support

- Convenient online submission

- Thorough peer review

- Inclusion in PubMed and all major indexing services

- Maximum visibility for your research

Submit your manuscript at www.biomedcentral.com/submit
Biomed Central 